\title{
Cell-free soluble expression of the membrane protein PsbS
}

\author{
M.Krishnan ${ }^{1}$, T.J.J.F. de Leeuw ${ }^{1}$ and A. Pandit ${ }^{1}{ }^{*}$ \\ 1 Dept. of Solid-State NMR, Leiden Institute of Chemistry, Leiden University, Einsteinweg 55, \\ 2300RA Leiden, The Netherlands \\ *corresponding author: a.pandit@chem.leidenuniv.nl
}

\begin{abstract}
Photosystem II subunit $\mathrm{S}$ (PsbS) is a membrane protein that plays an exclusive role in nonphotochemical quenching for photoprotection of plants under high-light conditions. The activation mechanism of PsbS and its pH-induced conformational changes are currently unknown. For structural investigation of PsbS, effective synthesis of PsbS with selective isotope or electron-spin labels or non-natural amino acids incorporated would be a great asset. This communication presents cell-free expression as a successful method for in vitro production of PsbS that would allow such incorporation. We have optimized the cell-free method to yield soluble PsbS of $\sim 500 \mathrm{ng} / \mu \mathrm{l}$ using a continuous-exchange method at $30^{\circ} \mathrm{C}$, along with a successful purification and refolding of PsbS in n-Dodecyl $\beta$-D-maltoside $(\beta$-DM) detergent. We expect that the presented protocols are transferrable for in vitro expression of other membrane proteins of the Light-Harvesting Complex family.
\end{abstract}

Keywords

In-vitro refolding, light harvesting, $\mathrm{pH}$ sensor, Photosystem II subunit $\mathrm{S}$ 
bioRxiv preprint first posted online Oct. 29, 2018; doi: http://dx.doi.org/10.1101/456087. The copyright holder for this preprint

(which was not peer-reviewed) is the author/funder, who has granted bioRxiv a license to display the preprint in perpetuity.

All rights reserved. No reuse allowed without permission.

\section{Introduction}

The discovery of Photosystem II subunit S (PsbS) has revealed that it has a prominent role in sensing changes in thylakoidal $\mathrm{pH}$. PsbS brings about structural rearrangements in the neighbouring photosynthetic proteins, leading to de-excitation of the antenna chlorophylls (Chls), which is known as the fast qE phase of non-photochemical quenching (NPQ) (Li et al. 2000; Li et al. 2004). PsbS is a $22 \mathrm{KDa}$ membrane protein with four transmembrane helices and belongs to the light harvesting complex (LHC) protein superfamily (Funk et al. 1995). PsbS can be overexpressed using E. coli and refolded into helical structures using several types of detergents (Wilk et al. 2013; Krishnan et al. 2017). Although this overexpression method is well established, there are challenges of inclusion bodies production, low yield while isotope and selective labelling, losses upon insertion into liposomes or nanodiscs and toxic effects to the host cells upon overexpression. Cell-free (CF) protein expression has emerged as an alternative technique for production of a diverse range of membrane proteins for functional studies (Reckel et al. 2008; Schwarz et al. 2008). In-vitro refolding of various membrane proteins during the CF reaction can be achieved by adding detergents, liposomes or lipid nanodiscs to the reaction mixture (Ishihara et al. 2005; Schwarz et al. 2008; Katzen et al. 2009). However, the yields for membrane proteins produced using the CF technique is still far below the yields achieved for soluble proteins (Liguori et al. 2007). We show that PsbS from Physcomitrella patens can be synthesised and successfully refolded by using a commercial CF system. Various detergents and lipid nanodiscs were added to the reaction mixtures to achieve soluble PsbS using fed-batch system. Purification and refolding of both pellet and soluble PsbS produced using CF reactions was successfully achieved in the detergent n-Dodecyl $\beta$-D-maltoside ( $\beta$-DM). 


\section{Materials and Methods}

Cell-free (CF) expression protocol

The PsbS gene from Physcomitrella patens (Krishnan et al. 2017) was inserted in a pExp5 vector for the CF reactions. Expressway ${ }^{\mathrm{TM}}$ Cell-Free Expression System (Invitrogen) was used to carry out the CF reactions We used $25 \mu \mathrm{l}$ reaction mixture (RM) containing the template DNA plasmid, incubated for $2-4$ hours at $30^{\circ} \mathrm{C}$ or $37^{\circ} \mathrm{C}$ unless states otherwise, while shaking at $1200 \mathrm{rpm}$. After 30 minutes, $25 \mu \mathrm{l}$ of feeding mixture (FM) was added into the reaction volume. To produce soluble PsbS, CF reactions were carried out in the presence of detergents, or in the presence of liposomes or lipid nanodiscs (preparation protocols according to (Crisafi and Pandit 2017)). In the batch feeding method, $12.5 \mu \mathrm{l}$ of FM was added every 30 minutes for up to 7 hours. In the continuous exchange (CE) method, $50 \mu \mathrm{l}$ of RM and $1 \mathrm{ml} \mathrm{FM}$ diluted in HEPES buffer was used for dialysis in $0.1 \mathrm{ml}$ 96-well microdialysis plates (Thermo Scientific - Pierce) containing a 10kDa cutoff membrane.

SDS-page gel analysis

SDS-page gel electrophoresis analysis $(12.5 \%$ running gel, $4 \%$ stacking gel stained with Coomassie brilliant blue R-250 Bio-Rad) was carried out to check the yield of PsbS synthesis along with $2.5 \mu \mathrm{l}$ of Precision Plus Protein ${ }^{\mathrm{TM}}$ Dual Color Standard from Sigma and BSA standard protein.

\section{Purification of CF-produced PsbS from pellet}

CF production of PsbS in the absence of detergents results in pellet containing PsbS. This pellet, $\mathrm{P}$, was subjected to urea wash protocol (Krishnan et al. 2017) to get rid of the impurities.

\section{Purification of CF-produced soluble PsbS}

Soluble PsbS was purified after completion of the CF reaction in the presence of $1 \%$ Brij or lipid nanodiscs using Ni-NTA Agarose beads (QIAGEN). The soluble fraction was diluted in equal amounts of binding buffer $\left(50 \mathrm{mM} \mathrm{NaH} \mathrm{PO}_{4}, 300 \mathrm{mM} \mathrm{NaCl}, 10 \mathrm{mM}\right.$ imidazole and appropriate detergent) and added to the resin, followed by 4 -hour incubation at $4{ }^{\circ} \mathrm{C}$. The supernatant was 
bioRxiv preprint first posted online Oct. 29, 2018; doi: http://dx.doi.org/10.1101/456087. The copyright holder for this preprint

removed from the resin by centrifuging for 1 minute at $200 \times \mathrm{xg} 4^{\circ} \mathrm{C}$ after the incubation step. Washing of the resin was carried out three times using 3 volumes of wash buffer (binding buffer + $20 \mathrm{mM}$ imidazole). The elution step was carried out 3 times using 1.5 volumes of elution buffer (binding buffer $+250 \mathrm{mM}$ imidazole) to achieve purified PsbS.

\section{Circular Dichroism (CD) spectroscopy}

A Jasco J-815 spectropolarimeter (Jasco Labortechnic, Germany) was used to perform CD spectroscopy to check the refolding of the CF-synthesized PsbS. The purified PsbS was buffer exchanged to $50 \mathrm{mM}$ mono-sodium phosphate, $\mathrm{pH} 8.0$ with appropriate detergent to remove the high salts and imidazole or urea concentrations. The spectra were recorded between $190 \mathrm{~nm}$ and $260 \mathrm{~nm}$ with a scanning rate of $100 \mathrm{~nm} / \mathrm{min}$, a response time of 8 seconds and an optical path length of $1 \mathrm{~mm}$.

\section{Results and discussion}

CF synthesis of PsbS as pellet

For carrying out the CF reaction, the PsbS plasmid was added to the CF E. coli reaction mix and incubated at $37^{\circ} \mathrm{C}$ for 3 hours. Using $1330 \mathrm{ng}$ of plasmid in the $\mathrm{CF}$ reaction, a yield of $200 \mathrm{ng} / \mu \mathrm{l}$ PsbS could be produced with this standard reaction protocol (Fig. S1). Since PsbS is a membrane protein, without the presence of detergents, the produced protein formed a pellet, P (Fig. 1a) in the reaction. Fig. 1b shows the purification of PsbS by washing with urea buffer (8M urea, 100mM Sodium Phosphate, 100mM Tris) to separate impurities (SS1 and SS2) from the pellet. Upon addition of $0.05 \%$ LDS, most of the PsbS from pellet was solubilized (SS3). Further addition of $0.5 \%$ LDS to the remaining pellet solubilized the remaining PsbS (SS4). The soluble fraction SS4 was buffer exchanged to remove the urea and stored in the buffer containing 0.1\% LDS for further use. Refolding of PsbS from SS4 was carried out in the presence of $0.12 \% \beta$-DM according to a published protocol and analysis of the refolded protein is discussed below (Wilk et al. 2013; Krishnan et al. 2017). 
(a)

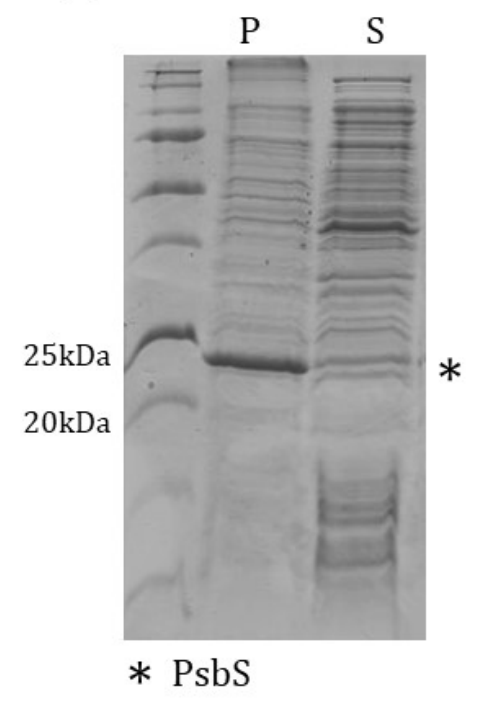

(b)

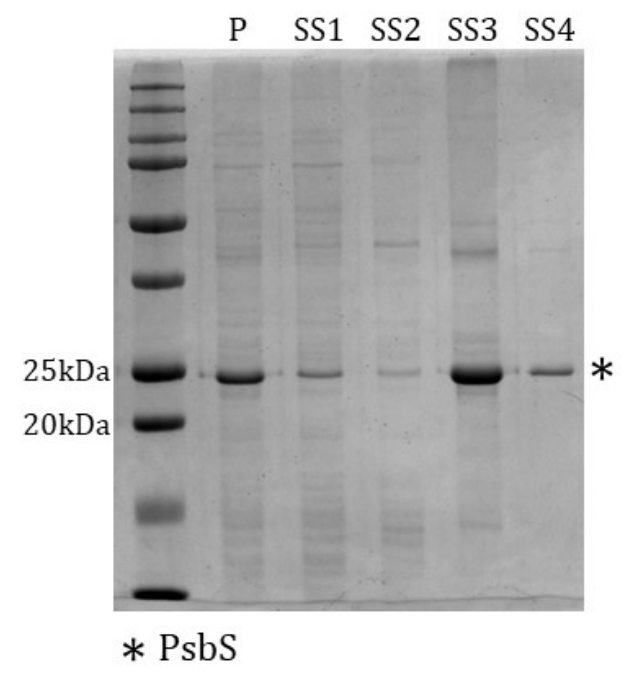

Fig 1 (a) CF production of PsbS $\left({ }^{*}\right)$ in the absence of detergents. CF reactions were separated in pellet (P), and supernatant (S). (b) Purification of CF PsbS from pellet: SS1 and SS2 are soluble fraction after washing the pellet P with 8M urea buffer, SS3 is the soluble fraction after washing with 8M urea buffer and $0.05 \%$ LDS and SS4 is the soluble fraction after washing with 8M urea buffer and 0.5\% LDS.

\section{CF synthesis of soluble PsbS}

In order to solubilize synthesized PsbS during the CF reaction, the effect of addition of various detergents to the reaction mix was analysed. We tested PsbS solubilization by carrying out the CF reaction in the presence of the detergents $\beta$-DM, Triton X-100, Brij-35 and Brij-78 (Fig. S2). Furthermore, addition of liposomes or lipid nanodiscs was tested as a method to directly fold synthesized PsbS into lipid membranes (Fig. S3 and Fig. S4). The results are summarized in Table 1 and show that successful production of PsbS was observed in the presence of all the tested detergents and in the presence of liposomes or lipid nanodiscs. In the presence of detergents, the produced protein still precipitated as a pellet, except for reactions carried out in the presence of sufficient amounts of polyoxyethylene-alkyl-ether detergents, Brij-35 and Brij-78. The flexible long chains of polyoxyethylene-alkyl-ethers and their relatively small hydrophilic head might be favouring the solubilisation of membrane proteins (Grip 1982; Garavito and Ferguson-Miller 2001; Külheim et al. 2002). Although some research studies showed that addition of liposomes was beneficial in improving membrane protein yield from CF reactions (Klammt et al. 2005), in our case the presence of asolectin liposomes lowered the production of PsbS considerably. 


\begin{tabular}{l|l|l|l|l}
\hline $\begin{array}{l}\text { Membrane mimicking } \\
\text { environment }\end{array}$ & $\begin{array}{l}\text { Concentration } \\
\text { mM (\%) }\end{array}$ & x CMC & Soluble & Pellet \\
\hline control &.. &. & - & ++ \\
$\beta$-DM & $0.51(0.03)$ & 4 & - & + \\
& $1.53(0.1)$ & 14 & - & + \\
& $3.06(0.2)$ & 28 & - & - \\
Triton X-100 (X100) & $0.23(0.15)$ & 10 & - & ++ \\
Brij-35 & $0.32(0.04)$ & 4 & $\square$ & $\square$ \\
& $1.6(0.2)$ & 20 & $\square$ & $\square$ \\
& $6.4(0.8)$ & 80 & $\square$ & $\square$ \\
Brij-78 & $9.2(1.0)$ & 200 & $\square$ & - \\
Asolectin liposomes & $24($ lipid) &. & $\square$ & $\square$ \\
Asolectin nanodiscs & $2.4($ lipid) &. & $\square$ & - \\
\hline
\end{tabular}

Table 1: CF expression of PsbS in membrane-mimicking environments. The reaction was carried out at $37^{\circ} \mathrm{C}$ and PsbS yield as soluble or pellet fraction was classified into four groups: -, no detectable expression; $\square$, spurious expression $<50 \mathrm{ng} / \mu \mathrm{l} ;+, 51-200 \mathrm{ng} / \mu \mathrm{l} ;++,>200 \mathrm{ng} / \mu \mathrm{l}$. SDS-page gels of the different reactions are presented in Fig. S1-S4 in the SI section.

\section{Incubation temperature}

The CF reactions were further optimized by varying the incubation temperature, testing reaction temperatures of $37^{\circ} \mathrm{C}, 30^{\circ} \mathrm{C}$ and $25^{\circ} \mathrm{C}$. Since Brij-78 was optimal for expression of soluble PsbS, this detergent was used in the temperature variance experiments. As shown in Fig. S5 and Table 2, reactions carried out at $30^{\circ} \mathrm{C}$ and $25^{\circ} \mathrm{C}$ gave a higher yield of $\mathrm{PsbS}$ than reactions at $37^{\circ} \mathrm{C}$, suggesting that lower temperatures are better suited, which could be due to a slower rate of protein translation. Because part of the produced $\mathrm{PsbS}$ was precipitated at $25^{\circ} \mathrm{C}$, for further experiments $30^{\circ} \mathrm{C}$ was selected as the optimal temperature for PsbS production in soluble form.

\begin{tabular}{l|l|l}
\hline Temp & Soluble & Pellet \\
\hline $37^{\circ} \mathrm{C}$ & $\square$ & - \\
$30^{\circ} \mathrm{C}$ & $+(+)$ & $\square$ \\
$25^{\circ} \mathrm{C}$ & + & + \\
\hline
\end{tabular}

Table 2: Temperature-dependent $\mathrm{CF}$ expression of PsbS. PsbS yield as soluble or pellet fraction was classified into four groups: -, no detectable expression; $\square$, spurious expression $<50 \mathrm{ng} / \mu \mathrm{l} ;+, 51-200 \mathrm{ng} / \mu \mathrm{l}$; ,$++>200 \mathrm{ng} / \mu \mathrm{l}$. 
bioRxiv preprint first posted online Oct. 29, 2018; doi: http://dx.doi.org/10.1101/456087. The copyright holder for this preprint (which was not peer-reviewed) is the author/funder, who has granted bioRxiv a license to display the preprint in perpetuity.

All rights reserved. No reuse allowed without permission.

\section{Batch feeding}

During the $\mathrm{CF}$ transcription and translation reactions, conditions change because of the consumption of substrates and accumulation of products and by-products, which inhibit the reaction itself. To upscale the PsbS production, batch feeding was tested. In this procedure, instead of adding $25 \mu \mathrm{l}$ of FM (feeding mix) after 30 minutes, $12.5 \mu \mathrm{l} \mathrm{FM}$ was added up to 10 times every 30 minutes after the reaction was started and the reaction was prolonged up to 8 hours. With this procedure, an amount of $23 \mu \mathrm{g}$ PsbS could be produced (Fig. 2). The total amount of protein was increased by batch feeding, but also required substantial more FM. Besides that, after 3 hours reaction time, white flakes were formed, suggesting that a part of PsbS was precipitated. The PsbS produced by CF batch feeding reactions in the presence of Brij-78 was purified for analysis (Fig. 2). In addition, we purified PsbS produced in lipid nanodiscs (Fig. S6).

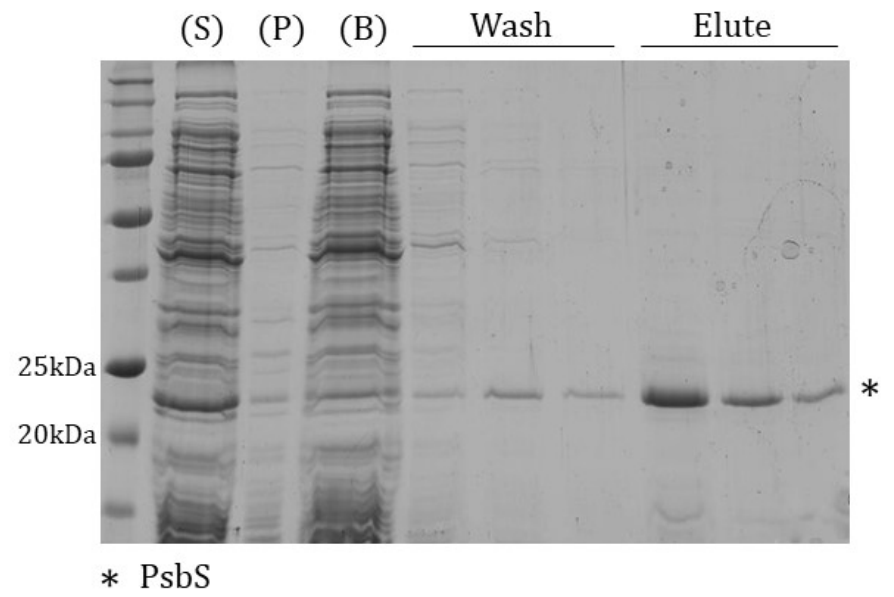

Fig 2 PsbS $(*)$ was expressed at $30^{\circ} \mathrm{C}$ in the presence of $1 \%$ Brij-78 using the batch feeding method; P, pellet and S, supernatant of the reaction mix before loading with Ni-NTA beads. B is the supernatant that was removed after incubation with Ni-NTA beads. Comparison of S and B shows a that most of the soluble PsbS binds to the beads. The beads were washed with buffer containing $20 \mathrm{mM}$ imidazole and PsbS was eluted with buffer containing $250 \mathrm{mM}$ of imidazole.

\section{Continuous exchange}

In order to avoiding precipitation during batch feeding and to improve the yield of CF production, we explored the use of continuous-exchange (CE) reactions, where dialysis is used to dilute the inhibitory products that are formed during the reaction in the FM when fresh amino acids and co- 
bioRxiv preprint first posted online Oct. 29, 2018; doi: http://dx.doi.org/10.1101/456087. The copyright holder for this preprint

(which was not peer-reviewed) is the author/funder, who has granted bioRxiv a license to display the preprint in perpetuity.

All rights reserved. No reuse allowed without permission.

factors are added. The CE reaction was carried out using $1 \%$ Brij-78 at $30^{\circ} \mathrm{C}$ for 9 hours with addition of $12.5 \mu \mathrm{FM}$ at three time-intervals. Using this set-up, the yield of PsbS was not significantly higher than with the batch-feeding method, but the PsbS did remain in a soluble state. The results are shown in Fig. S7. The yield of PsbS in this reaction was estimated to be $\sim 500$ $\mathrm{ng} / \mu \mathrm{l}$ and could be further improved by further increasing the reaction time.

\section{CD spectroscopy of refolded CF-produced PsbS}

To check the fold of the CF produced soluble PsbS, UV-CD spectroscopy was carried out by pooling the eluted fractions of PsbS shown in Fig. 2. The initial CD spectrum of the CF-produced PsbS in Brij-78 suggests that the soluble PsbS is in a partly folded molten-globule state and does not show the characteristics of $\alpha$-helix structure (Fig. S8). To overcome this issue, we first unfolded the PsbS by removal of Brij- 78 in the presence of $0.1 \%$ LDS followed by refolding in the presence of $0.12 \% \beta$-DM using the standard refolding protocol (Wilk et al. 2013; Krishnan et al. 2017). In addition, PsbS pellets produced from the CF reaction carried out in the absence of detergent (Fig. 1) were refolded using the standard protocol. The CD spectra of CF-produced, refolded PsbS are shown in Fig. 3. According to the CD spectral analysis, the refolded PsbS has $\sim 50 \%$ helical structure (Table 3 ). This number is in agreement with the crystal structure of spinach PsbS that shows that PsbS is $\sim 48 \% \alpha$-helical, with the remaining part random coil and a small contribution of $\beta$-sheet (Fan et al. 2015), and is consistent with CD analyses of detergentrefolded PsbS produced from E. coli (Krishnan et al. 2017). Comparing the CD spectrum of CFproduced PsbS in $\beta$-DM to the CD spectrum of $E$. coli produced PsbS in $\beta$-DM, different amplitudes for the characteristic bands at $210 \mathrm{~nm}$ and $222 \mathrm{~nm}$ are observed. In previous work, we demonstrated that the PsbS CD signature varies for different detergent types, while the estimated helical content is similar. The variations in the CD spectra were attributed to differences in the stromal loop and tail structures of which the folds may depend on the detergent microenvironment. The CD spectra of $E$. coli and CF produced PsbS that are compared in Fig. 3 however 
bioRxiv preprint first posted online Oct. 29, 2018; doi: http://dx.doi.org/10.1101/456087. The copyright holder for this preprint (which was not peer-reviewed) is the author/funder, who has granted bioRxiv a license to display the preprint in perpetuity.

All rights reserved. No reuse allowed without permission.

are both taken from samples where PsbS is solubilized in $\beta$-DM. The observed differences could originate from the presence of lipids from the E. coli host system in the E. coli produced PsbS as NMR spectra show the presence of protein-associated lipids that are purified along with the protein (data not shown). We suspect that lipids mediate the refolding of PsbS and influence the conformations of the non-helical contents. The influence of lipids on the refolding of membrane proteins is an interesting aspect, which is not easily controlled in recombinant expression systems using host cells, but which could be further explored in CF synthesis, where selective lipids can be added to the synthesis reaction or during the subsequent refolding steps.

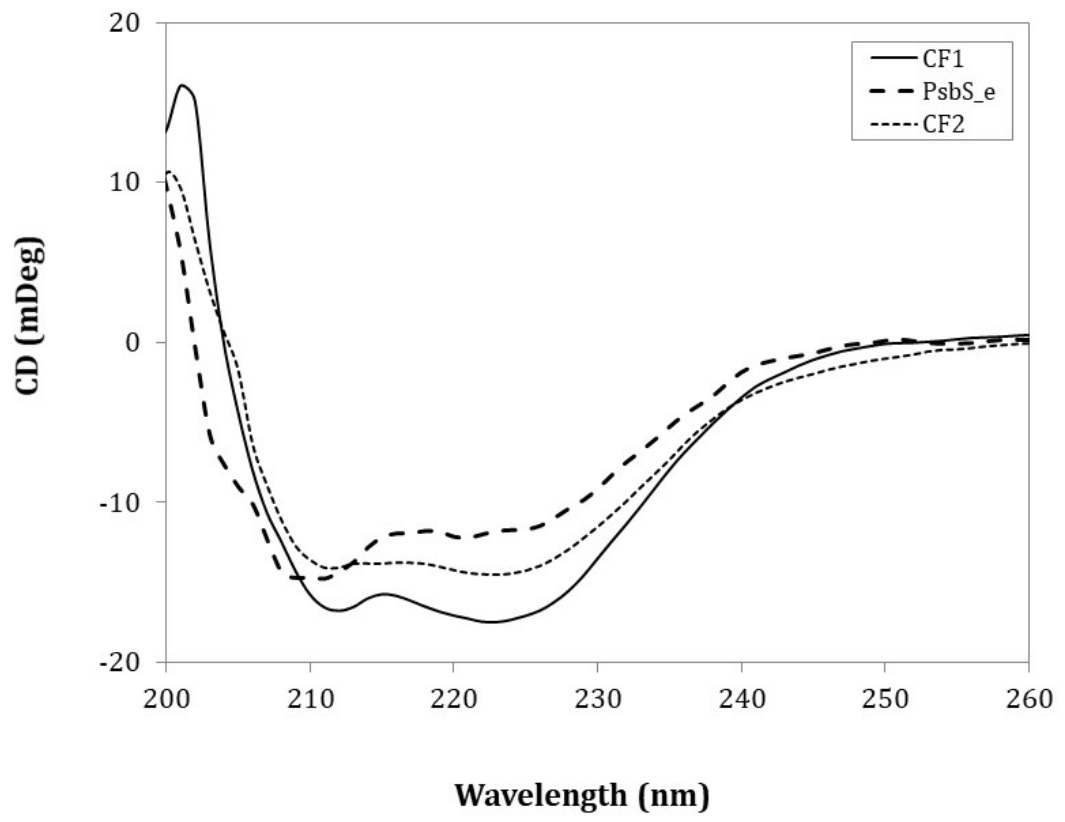

Fig 3 CD spectra of cell free produced PsbS in comparison with E. coli produced PsbS refolded in $0.12 \% \beta$-DM. CF1 is PsbS produced with Brij-78 and refolded in $\beta$-DM. CF2 was produced without a detergent as a pellet, purified and refolded in $\beta$-DM, PsbS_e was produced from $E$. coli, purified and refolded in $\beta$-DM.

\begin{tabular}{llll}
\hline $\begin{array}{l}\text { Secondary } \\
\text { structures (\%) }\end{array}$ & PsbS_e & CF1 & CF2 \\
\hline Helix & 51.4 & 54.9 & 50.4 \\
Antiparallel & 30.5 & 7.7 & 0.9 \\
Parallel & 0 & 10.9 & 27.1 \\
Turn & 2.3 & 14.8 & 3.8 \\
Others & 15.8 & 11.8 & 17.9 \\
\hline
\end{tabular}

Table 3. Estimation of secondary structures using BeStSel (Beta Structure Selection (Micsonai et al. 2015)). 
bioRxiv preprint first posted online Oct. 29, 2018; doi: http://dx.doi.org/10.1101/456087. The copyright holder for this preprint

\section{Conclusions}

We demonstrate that with CF synthesis, PsbS can be produced either as aggregate pellet or in a soluble state in the presence of membrane-mimicking additives, in contrast to the $E$. coli overexpression, where PsbS is always secreted in inclusion bodies. The CF produced PsbS protein could successfully be refolded into detergent micelles, showing $\sim 50 \%$ helical content. The protocols were optimized to yield $\sim 500 \mathrm{ng} / \mu \mathrm{l}$ PsbS production in a single reaction, which could be upscaled for structural studies to produce milligram amounts of protein.

\section{Acknowledgements}

We would like to thank Nora Goosen and Geri Moolenaar for their technical help and advice and Emanuela Crisafi for providing the liposomes. A.P. and M.K. were financially supported by a CWVIDI grant of the Netherlands Organization of Scientific Research (grant nr. 723.012.103).

\section{Conflict of Interest}

The authors declare that they have no conflict of interest. 
bioRxiv preprint first posted online Oct. 29, 2018; doi: http://dx.doi.org/10.1101/456087. The copyright holder for this preprint (which was not peer-reviewed) is the author/funder, who has granted bioRxiv a license to display the preprint in perpetuity. All rights reserved. No reuse allowed without permission.

\section{References}

Crisafi, Emanuela; Pandit, Anjali (2017): Disentangling protein and lipid interactions that control a molecular switch in photosynthetic light harvesting. In Biochimica et Biophysica Acta Biomembranes 1859 (1), pp. 40-47. DOI: 10.1016/j.bbamem.2016.10.010.

Fan, Minrui; Li, Mei; Liu, Zhenfeng; Cao, Peng; Pan, Xiaowei; Zhang, Hongmei et al. (2015): Crystal structures of the PsbS protein essential for photoprotection in plants. In Nature structural and molecular biology 22 (9), pp. 729-735. DOI: 10.1038/nsmb.3068.

Funk, C.; Schroëder, W. P.; Napiwotzki, A.; Tjus, S. E.; Renger, G.; Andersson, B. (1995): The PS IIS protein of higher plants : a new type of pigment binding protein. In Biochemistry 34, pp. 11133-11141.

Garavito, R. Michael; Ferguson-Miller, Shelagh (2001): Detergents as Tools in Membrane Biochemistry. In Journal of Biological Chemistry 276 (35), pp.32403-32406. DOI: 10.1074/jbc.R100031200.

Grip, Willem J.De (1982): Thermal stability of rhodopsin and opsin in some novel detergents. In : Methods in Enzymology: Elsevier, pp. 256-265.

Ishihara, Goshi; Goto, Mie; Saeki, Mihoro; Ito, Kaori; Hori, Tetsuya; Kigawa, Takanori et al. (2005): Expression of G protein coupled receptors in a cell-free translational system using detergents and thioredoxin-fusion vectors. In Protein Expression and Purification 41 (1), pp. $27-$ 37. DOI: 10.1016/j.pep.2005.01.013.

Katzen, Federico; Peterson, Todd C.; Kudlicki, Wieslaw (2009): Membrane protein expression: no cells required. In Trends in Biotechnology 27 (8), pp.455-460. DOI: 10.1016/j.tibtech.2009.05.005.

Klammt, Christian; Schwarz, Daniel; Fendler, Klaus; Haase, Winfried; Do, Volker; Bernhard, Frank (2005): Evaluation of detergents for the soluble expression of alpha -helical and betabarrel-type integral membrane proteins by a preparative scale individual cell-free expression system 272 (10), pp. 6024-6038. DOI: 10.1111/j.1742-4658.2005.05002.x.

Krishnan, Maithili; Moolenaar, Geri F.; Gupta, Karthick Babu Sai Sankar; Goosen, Nora; Pandit, Anjali (2017): Large-scale in vitro production, refolding and dimerization of PsbS in different microenvironments. In Scientific Reports 7 (1), pp. 1-11. DOI: 10.1038/s41598-017-15068-3.

Külheim, Carsten; Agren, Jon; Jansson, Stefan (2002): Rapid regulation of light harvesting and plant fitness in the field. In Science (New York, N.Y.) 297 (5578), pp.91-93. DOI: 10.1126/science.1072359. 
bioRxiv preprint first posted online Oct. 29, 2018; doi: http://dx.doi.org/10.1101/456087. The copyright holder for this preprint

Li, X. P.; Björkman, O.; Shih, C.; Grossman, A. R.; Rosenquist, M.; Jansson, S.; Niyogi, K. K. (2000): A pigment-binding protein essential for regulation of photosynthetic light harvesting. In Nature 403 (6768), pp. 391-395. DOI: 10.1038/35000131.

Li, Xiao Ping; Gilmore, Adam M.; Caffarri, Stefano; Bassi, Roberto; Golan, Talila; Kramer, David; Niyogi, Krishna K. (2004): Regulation of photosynthetic light harvesting involves intrathylakoid lumen pH sensing by the PsbS protein. In Journal of Biological Chemistry 279, pp. 22866-22874. DOI: $10.1074 /$ jbc.M402461200.

Liguori, Lavinia; Marques, Bruno; Villegas-Méndez, Ana; Rothe, Romy; Lenormand, Jean Luc (2007): Production of membrane proteins using cell-free expression systems. In Expert Review of Proteomics 4 (1), pp. 79-90. DOI: 10.1586/14789450.4.1.79.

Micsonai, A.; Wien, F.; Kernya, L.; Lee, Y. H.; Goto, Y.; Refregiers, M.; Kardos, J. (2015): Accurate secondary structure prediction and fold recognition for circular dichroism spectroscopy. In Proceedings of the National Academy of Sciences of the United States of America 112 (24). DOI: 10.1073/pnas.1500851112.

Reckel, Sina; Sobhanifar, Solmaz; Schneider, Birgit; Junge, Friederike; Schwarz, Daniel; Durst, Florian et al. (2008): Transmembrane segment enhanced labeling as a tool for the backbone assignment of alpha-helical membrane proteins. In Proceedings of the National Academy of Sciences of the United States of America 105 (24), pp.8262-8267. DOI: 10.1073/pnas.0710843105.

Schwarz, Daniel; Dötsch, Volker; Bernhard, Frank (2008): Production of membrane proteins using cell-free expression systems. In Proteomics 8 (19), pp.3933-3946. DOI: 10.1002/pmic.200800171.

Wilk, Laura; Grunwald, Matthias; Liao, Pen-Nan; Walla, Peter Jomo; Kühlbrandt, Werner (2013): Direct interaction of the major light-harvesting complex II and PsbS in nonphotochemical quenching. In Proceedings of the National Academy of Sciences of the United States of America 110 (14), pp. 5452-5456. DOI: 10.1073/pnas.1205561110. 